\title{
FAKTOR-FAKTOR MOTIVASI REMAJA BERWIRAUSAHA MELALUI BISNIS ONLINE DI BATUAMPAR PELAIHARI
}

\author{
Akhmad Samhudi ${ }^{1}$ \\ akhmadsamhudiuniska@gmail.com
}

Siti Rizki Pardani ${ }^{2}$

tetehraesa@gmail.com

Fakultas Ekonomi Universitas Islam Kalimantan MAB Banjarmasin

\begin{abstract}
The number of conveniences in shopping online and the various types of products and services offered, make the Indonesian people make Online Shops as one of the new "shopping places" besides shopping centers.

This study aims to determine and prove the motivational factors of Batu Ampar Pelaihari teenagers in entrepreneurship through online business.

This type of research is descriptive quantitative. The data studied in this study were sourced from primary data and secondary data. The number of respondents who were used as observations in this study amounted to 40 people. Statistical analysis using simple linear, with testing tools using SPSS software version 20.00

The results show that motivational factors can influence adolescent entrepreneurship in Batu Ampar Pelaihari. Variable data which is a simple conceptual path where motivation $(\mathrm{X}) /$ independent variable and entrepreneurial (Y) / dependent variable.

The independent variable has a unidirectional relationship with the dependent variable because the independent variable has a positive coefficient, meaning that if the $\mathrm{x}$ variable increases, the $\mathrm{y}$ Variable also increases and vice versa.
\end{abstract}

Kata Kunci : Faktor-faktor Motivasi, wirausaha remaja 


\section{PENDAHULUAN}

Perkembangan online shop atau toko online melalui media internet sudah menjamur di Indonesia, bahkan sudah sangat dikenal baik oleh khalayak ramai. Banyaknya beragam kemudahan dalam berbelanja dan bermacam jenis produk dan jasa yang ditawarkan, membuat masyarakat Indonesia menjadikan Online Shop sebagai salah satu "tempat berbelanja" baru selain pusat perbelanjaan. Hal ini membuat banyak penjual Online Shop yang berlomba-lomba menawarkan produknya dengan berbagai cara untuk menarik konsumen berbelanja, mereka memanfaatkan keadaan dimana Online Shop saat ini sedang diminati masyarakat Indonesia sampai saat ini.

Kelebihan-kelebihan dari Online Shop inilah yang menyebabkan bisnis online menjadi tren yang sangat luar biasa, dalam lima tahun terakhir bisnis via internet semakin menggurita. Bahkan perusahaan-perusahaan besar pada akhirnya menggunakan Online Shop sebagai citra diri perusahaan untuk lebih menjangkau konsumennya.

Kecamatan Batu Ampar pemekaran dari sebagian wilayah Kecamatan Pelaihari dan sebagian dari wilahah Kecamatan Jorong, yang pendiriannya didirikan menurut dasar hukumnya Peraturan Pemerintah Nomor 28 tahun 1995. Mayoritas remaja pada desa ini sebelumnya bekerja sebagai karyawan pertambangan batu bara yang ada di sekitar Batu Ampar, seperti jorong, Asam-Asam, Batu Licin hingga Kotabaru Kalimantan Selatan, namun belakangan ini banyaknya pengurangan karyawan dari perusahaan pertambangan yang ada di Kalimantan Selatan diakibatnya berkurangnya permintaan akan batubara mendorong karyawan yang terkena dampak pemutusan hubungan kerja tersebut untuk berwirausaha, salag satunya adalah berwirausaha dengan online, karena bisnis ini diyakini akan lebih mudah karena tidak bermodal banyak dan mengharuskan memiliki toko, hanya bermodal koneksi internet sudah bisa berjualan melalui online bisnis.

Berdasarkan uraian di atas, maka penulis tertarik untuk mengangkat hal-hal tersebut dengan judul "Analisis Faktor-Faktor Yang Memotivasi Remaja Berwirausaha Melalui Bisnis Online Di Batu Ampar Pelaihari”. 


\section{TINJAUAN PUSTAKA}

\section{Indikator Motivasi Kerja}

Berikut teori Motivasi Interinsik "dua faktor" menurut Herzberg yang dapat dijadikan sebagai acuan guna mengukur Motivasi Interinsik yang dikutip oleh Siagian (2012) dan Widyanti, R (2021) adalah sebagai berikut :

Teori Motivasi Interinsik “Dua Faktor” Menurut Herzberg

\begin{tabular}{|l|ll|}
\hline \multicolumn{1}{|c|}{ Faktor Eksterinsik } & \multicolumn{2}{|c|}{ Faktor Interinsik } \\
\hline 1. Kebijakan dan Administrasi & 1. & Keberhasilan \\
2. Supervisi & 2. & Pengakuan / Penghargaan \\
3. Gaji / upah & 3. & Pekerjaan itu sendiri \\
4. Hubungan antar pribadi & 4. & Tanggung jawab \\
5. Kondisi Kerja & 5. & Pengembangan \\
\hline
\end{tabular}

Disimpulkankan dari berbagai sumber

Herzberg memandang bahwa kepuasan kerja berasal dari keberadaan motivator interinsik dan bawa ketidakpuasa kerja berasal dari ketidakberadaan faktor-faktor eksterinsik.

\section{Wirausaha}

Pengertian wirausaha berdasarkan pendapat Stephen P. Robbins dan Mary Coulter (2010) adalah proses dimana seseorang atau sekelompok orang menggunakan usaha dan sarana yang terorganisasi untuk mengejar peluang guna menciptakan nilai dan bertumbuh dengan memenuhi keinginan dan kebutuhan melalui inovasi dan keunikan. Josseph C. Schumpeter menyatakan bahwa seorang wirausaha adalah orang yang mampu menghancurkan keseimbangan pasar yang baru dan mengambil keuntungan-keuntungan atas perubahan-perubahan tersebut.

Berdasarkan pendapat Retno Dewanti (2008) wirausahawan secara umum adalah orang-orang yang mampu menjawab tantangan-tantangan dan memanfaatkan peluang-peluang yang ada. Berdasarkan beberapa pendapat ahli yang telah disampaikan sebelumnya maka dapat ditarik kesimpulan bahwa wirausaha adalah sebuah pemikiran yang inovatif, kreatif, yang 
dijalankan dengann memperhitungkan resiko-resiko yang akan dihadapinya dalam persaingan bisnis di sebuah industri yang akan dimasukinya. Seorang wirausaha merupakan seseorang yang dapat memberiinovasi, kreatifitas, memimpin dan juga mengarahkan apa yang menjadi bisnisnya saat itu. Pengetahuan manajemen sangat penting dimiliki oleh individu yang bertindak sebagai pengambil keputusan (Basuki, 2015).

Dalam sebuah penelitian yang dilakukan oleh Gheorghe Savoiu (2010) dan Basuki (2015) menyebutkan bahwa terdapat empat hal yang perlu dimiliki oleh seorang wirausahawan yaitu :

1) Proses ide, inovasi, dan kreasi yaitu memiliki ide untuk membuat inovasi atau mengkreasikan sesuatu yang baru dengan menambahkan nilainya. Pertambahan nilai ini tidak hanya diakui oleh wirausahawan semata namun juga pasar yang akan menggunakan hasil inovasi/kreasi tersebut.

2) Komitmen yang tinggi semakin besar fokus dan perhatian yang diberikan dalam usaha ini maka akan mendukung proses inovasi dan kreasi yang akan timbul dalam kewirausahaan.

3) Memperkirakan resiko. Dalam hal ini resiko yang mungkin terjadi berkisar pada resiko keuangan, fisik dan resiko sosial.

4) Memperoleh reward. Dalam hal ini reward yang terpenting adalah independensi atau kebebasan yang diikuti dengan kepuasan pribadi. Sedangkan reward berupa materi biasanya dianggap sebagai suatu bentuk derajat dalam mengukur kesuksesan usahanya.

\section{Bisnis Online Shop (Toko Online)}

Online Shop menjadi bisnis yang berpeluang besar karena tidak adanya batas pasar. Semua orang di seluruh penjuru dunia dapat mengakses bisnis website kita. Pasar menjadi sangat besar. Bisnis ini juuga buka 24 jam, dan tidak membatasi waktu. Bisnis online memang berbeda dengan bisnis konvensional, yang membedakan adalah sarana yang digunakan. Jika dalam bisnis konvensional (offline), para pihak yang berperan dalam bisnis bertemu dan berinteraksi langsung di suatu tempat di dunia nyata, maka pada bisnis online para pihak yang berperan dalam dunia bisnis online bertemu dan 
berinteraksi di dunia maya melalui internet tanpa batasan waktu dan wilayah. Salah satu faktor terpenting dalam bisnis online adalah kepercayaan. Artinya, antara pihak harus memiliki rasa kepercayaan terhadap satu sama lain. Selama menjalankan bisnis online, antara pihak memang tidak bertemu secara langsung/pribadi (2009:31:32).

Untuk pasar Indonesia sendiri peluang bisnis online sangat menggiurkan. Hal ini dikarenakan pengguna internet di Indonesia semakin lama semakin bertambah pesar.

\section{Pemasaran Bisnis Online}

Dalam pemasarannya biasanya online shopper memanfaatkan beberapa layanan dan aplikasi yang tersedia dalam komputer ataupun smartphone yang mereka miliki, antara lain seperti :

1) Facebook

Facebook merupakan situs jejaring sosial yang saat ini sedang booming di dunia maya. Facebook merupakan karya dari Mark Elliot Zuckerberg bersama kawannya, Dustin Moskovitz dan Chris Hughes, saat belajar di Harvard University pada tahun 2004. Pada Februari 2004, Zuckerberg meluncurkan program tersebut dan langsung disambut hangat oleh siswa di Amerika Serikat dengan langsung membuka account facebook. Pada tahun 2005, Zuckerberg resmi menakan perusahaannya yaitu Facebook. Awalnya facebook dikenal dari mulut ke mulut di antara para siswa di Amerika Serikat, selanjutnya menyebar ke sekolah lain dan Universitas lain di Amerika Serikat, sampai akhirnya terkenal di seluruh dunia. Nilawati (2010:1)

2) Twitter

Twitter hingga saat ini masih menjadi kenikmatan tersendiri untuk para neeter. Sudah banyak pengguna internet yang beralih menggunakan layanan ini. Ada banyak hal tentunya yang menyebabkan perubahan gaya hidup masyarakat internet dengan memutuskan migrasi ke dalam twitter. Mulai dari tampilan yang simpel dan mudah dioperasikan hingga fitur realtime yang interaktif. Karena perkembangannya, maka banyak sekali 
layanan atau aplikasi yang beredar di dalam internet untuk semakin memudahkan user dalam memanfaatkan layanan twitter ini. Madcoms (2010:1)

3) Instagram

Instagram merupakan salah satu aplikasi atau fitur unggulan yang ada di smartphone yang memudahkan para pengguna untuk berbagi foto. Sistem sosial di dalam instagram adalah dengan menjadi pengikut akun pengguna lainnya, atau memiliki pengikut instagram. Dengan demikian, interaksi antara sesama pengguna instagram sendiri dapat terjalin dengan memberikan tanda suka dan juga mengomentari foto-foto yang telah diunggah oleh pengguna lainnya. Kebanyakan dari pelaku bisnis ini lebih suka menggunakan layanan ini, hal ini dikareakan instagram dalam meng-share foto-foto langsung bisa ditautkan dengan facebook dan twitter, sehingga mereka tidak perlu membagikan foto-foto produknya satu persatu dari berbagai macam layanan, dengan instagram semua langsung bisa diatasi. Hal ini sangat memudahkan pebisnis dalam mempromosikan produknya karena sangat hemat waktu.

\section{METODE PENELITIAN}

Jenis Penelitian ini merupakan penelitian deskriptif kuantitatif yang bermaksud menjelaskan hubungan kausal antar variabel melalui pengujian hipotesis. Sehingga penelitian ini termasuk dalam jenis eksplanatori yaitu jenis penelitian yang bertujuan mencari potensi-potensi hubungan-hubungan antara satu variabel dengan variabel lainnyaatau bagaimana suatu variabel mempengaruhi variabel lainnya. (Basuki, 2021).

Populasi dalam penelitian ini adalah seluruh Remaja di Batu Ampar yanng berusia 18 sampai 22 tahun yang berbisnis online yaitu berjumlah 40 (empat puluh) orang. Seluruhnya dijadikan responden atau sampel jenuh.

Uji validitas instrument menggunakan teknik korelasi product moment dari Pearson dengan nilai > 0,3 (Basuki, 2021). Uji Reliabilitas Instrumen menggunakan koefisien alpha cronbach dengan nilai > 0,6 (Sekaran, 2006) 
Analisis statistik menggunakan Regresi linier sederhana terdiri atas dua variabel. Satu variabel yang berupa variabel terikat/tergantung diberi simbol $\mathrm{Y}$ dan dari kedua yang berupa variabel bebas diberi simbol X. regresi sederhana ini menyatakan hubungan kausalitas antara dua variabel dan memperkirakan nilai variabel terikat berdasarkan nilai variabel bebas.

\section{HASIL DAN PEMBAHASAN}

\section{Hasil Penelitian}

\section{1) Karakteristik Responden}

Karakteristik responden adalah untuk mengetahui data responden yang dijadikan sampel dalam penelitian ini yang meliputi jenis kelamin, umur, status, dan pendidikan.

(1) Jenis Kelamin

Tabel 4.1

Karakteristik Responden Berdasarkan Jenis Kelamin

\begin{tabular}{|c|l|c|c|}
\hline No & \multicolumn{1}{|c|}{ Jenis Kelamin } & $\begin{array}{c}\text { Frekuensi } \\
\text { (orang) }\end{array}$ & Persen (\%) \\
\hline 1 & Laki-Laki & 18 & $45 \%$ \\
\hline 2 & Perempuan & 22 & $55 \%$ \\
\hline \multicolumn{2}{|c|}{ Total Responden } & 40 & 100 \\
\hline
\end{tabular}

Sumber : data primer, diolah (2021)

Responden dalam penelitian ini adalah 18 orang (45\%) adalah Laki-Laki dan 22 orang (55\%) adalah perempuan.

(2) Umur

Tabel 4.2

Karakteristik Responden Berdasarkan Umur

\begin{tabular}{|c|l|c|c|}
\hline No & \multicolumn{1}{|c|}{ Jenis Kelamin } & $\begin{array}{c}\text { Frekuensi } \\
\text { (orang) }\end{array}$ & Persen (\%) \\
\hline 1 & Dibawah 20 Tahun & 0 & $0 \%$ \\
\hline 2 & $20-30$ Tahun & 40 & $100 \%$ \\
\hline 3 & $31-40$ Tahun & 0 & $0 \%$ \\
\hline 4 & 40 Tahun Ke atas & 0 & $0 \%$ \\
\hline \multicolumn{2}{|c|}{ Total Responden } & 40 & 100 \\
\hline
\end{tabular}

Sumber :data primer, diolah (2021) 
Responden dalam penelitian ini adalah sebanyak 40 orang $(100 \%)$ berusia $20-30$ Tahun.

(3) Status

Tabel 4.3

Karakteristik Responden Berdasarkan Status

\begin{tabular}{|c|l|c|c|}
\hline No & \multicolumn{1}{|c|}{ Jenis Kelamin } & $\begin{array}{c}\text { Frekuensi } \\
\text { (orang) }\end{array}$ & Persen (\%) \\
\hline 1 & Belum Kawin & 36 & $90 \%$ \\
\hline 2 & Kawin & 4 & $10 \%$ \\
\hline 3 & Janda / Duda & 0 & $0 \%$ \\
\hline \multicolumn{2}{|c|}{ Total Responden } & 40 & 100 \\
\hline
\end{tabular}

Sumber : data primer, diolah (2021)

Responden dalam penelitian ini 36 orang (90\%) belum kawin dan 4 orang (10\%) kawin.

(4) Pendidikan Terakhir

Tabel 4.4

Karakteristik Responden Berdasarkan Pendidikan

\begin{tabular}{|c|l|c|c|}
\hline No & Jenis Kelamin & $\begin{array}{c}\text { Frekuensi } \\
\text { (orang) }\end{array}$ & Persen (\%) \\
\hline 1 & SD dan SLTP & 0 & $0 \%$ \\
\hline 2 & SLTA & 28 & $70 \%$ \\
\hline 3 & Diploma & 1 & $3 \%$ \\
\hline 4 & Sarjana & 11 & $28 \%$ \\
\hline 5 & Pasca Sarjana & 0 & $0 \%$ \\
\hline \multicolumn{2}{|c|}{ Total Responden } & 40 & 100 \\
\hline
\end{tabular}

Sumber : data primer, diolah (2021)

Responden dalam penelitian ini adalah 28 orang (70\%) berpendidikan SLTA, 1 orang (3\%) berpendidikan Diploma, 11 orang (28\%) berpendidikan Sarjana.

(1) Validitas dan Reliabilitas

Hasil uji validitas dan reabilitas instrument penelitian dapat dilihat pada tabel 4.7 dibawah ini : 
Tabel 4.7

Rekapitulasi Hasil Uji Validasi dan Reliabilitas Instrumen Penelitian

\begin{tabular}{|c|l|l|r|l|l|c|c|}
\hline Variabel & Item & $\mathrm{R}$ & $\mathrm{r}_{\text {syarat }}$ & Keterangan & $\alpha$ & $\alpha_{\text {minimal }}$ & Keterangan \\
\hline \multirow{4}{*}{$\begin{array}{c}\text { Motivasi } \\
(\mathrm{X})\end{array}$} & $\mathrm{X} .1$ & 0.938 & 0.3 & Valid & & & \\
& $\mathrm{X} .2$ & 0.938 & 0.3 & Valid & 0.965 & 0.6 & Reliabel \\
\cline { 2 - 6 } & $\mathrm{X} .3$ & 0.981 & 0.3 & Valid & & & \\
\hline \multirow{4}{*}{$\begin{array}{c}\text { Wirausaha } \\
\text { (Y) }\end{array}$} & $\mathrm{Y} .1$ & 0.622 & 0.3 & Valid & & & \\
\cline { 2 - 5 } & Y.2 & 0.732 & 0.3 & Valid & \multirow{3}{*}{0.858} & 0.6 & Reliabel \\
\cline { 2 - 5 } & Y.3 & 0.882 & 0.3 & Valid & & & \\
\cline { 2 - 5 } & Y.4 & 0.764 & 0.3 & Valid & & & \\
\hline
\end{tabular}

Sumber : Lampiran 4

Berdasarkan tabel 4.7 diatas maka menunjukkan bahwa semua item pertanyaan pada variabel independent dan dependent memiliki nilai korelasi lebih besar dari $\mathrm{r}_{\text {syarat, }}$ instrume penelitian dapat dikatakan valid apabila koefisien korelasinya $>$ dari 0,3. Sugiyono dalam Basuki (2021) dapat disimpulkan bahwa semua item pertanyaan adalah valid.

Uji Reabilitas dilakukan dengan tujuan untuk menguji sejauh mana alat pengukur dapat diandalkan atau dipercaya. Dalam penelitian ini nilai reabilitas suatu instrumen diterima jika memiliki Alpha Cronbach minimal 0,6. Arikunto dalam Supriyanto dan Machfudz (2010:296), maka dapat disimpulkan bahwa semua item pertanyaan adalah reliabel (dapat diandalkan atau dipercaya).

\section{Pembahasan}

\section{1) Analisis Regresi Sederhana Motivasi (X) terhadap Wirausaha (Y)}

Pengujian dilakukan dengan tingkat kepercayaan 95\% atau tingkat signifikansi $0,05(\mathrm{a}=0,05)$ dan rumus $\mathrm{df}=\mathrm{n}-\mathrm{K}-1=40-2-1=37$ maka didapat nilai $\mathrm{t}$ tabel sebesar 2,026. Adapun rekapitulasi regresi linier berganda dalam penelitian ini adalah sebagai berikut : 
Tabel 4.8

Rekapitulasi Analisis Regresi Linier Sederhana

Faktor-Faktor Motivasi (X) Terhadap Wirausaha (Y) Remaja

Batu Ampar Pelaihari Yang Berbisnis Online

\begin{tabular}{|l|l|l|l|l|c|}
\hline \multicolumn{1}{|c|}{ Variabel } & $\begin{array}{c}\text { Koefisien } \\
\text { Regresi } \\
(\mathrm{bi})\end{array}$ & $\begin{array}{c}\text { Standar } \\
\text { Error }\end{array}$ & $\mathrm{T}$ & $\begin{array}{c}\text { T tabel } \\
\text { df } 37\end{array}$ & Sig \\
\hline Konstanta & 10,979 & & \\
\hline Motivasi $(\mathrm{X})$ & 0,585 & 0,161 & 3,642 & 2,026 & 0,001 \\
\hline Konstanta $=10,979$ & \\
Multiple $\mathrm{R}=0,509$ \\
$\mathrm{R}$ square $\left(\mathrm{R}^{2}\right)=0,259$ \\
Sig $=0,001$
\end{tabular}

Sumber : Lampiran 4

Berdasarkan Tabel 4.8 diatas dapat dilihat $\mathrm{R}$ square sebesar 0,259 yang berarti besarnya variasi sumbangan variabel Motivasi terhadap variavel Wirausaha adalah $25,9 \%$ sedangkan sisanya $74,1 \%$ dijelaskan oleh sebab lain diluar dari penelitian.

Pada model regresi linier ini, akan dilihat besarnya kontribusi untuk variabel bebas terhadap variabel terikatnya dengan melihat besarnya koefisien determinasi totalnya (R2). Jika R2 yang diperoleh mendekati 1 (satu) maka dapat dikatakan semakin kuat model tersebut menerangkan hubungan variabel bebas terhadap variabel terikat.

Sebaliknya jika R2 makin mendekati 0 (nol) maka semakin lemah pengaruh variabel-variabel bebas terhadap variabel terikat.

Berdasarkan tabel 4.7 berdasarkan nilai-nilai tersebut diatas maka dapat ditentukan model regresi linier sederhana yang dinayatakan dalam persamaan sebagai berikut :

$\mathrm{Y}=\mathrm{a}+\mathrm{bx}$

$\mathrm{Y}=10,979+0,585 \mathrm{x}$

Berdasarkan persamaan tersebut, menunjukkan bahwa variabel bebas memiliki koefisien regresi positif. Hal ini berarti variabel Motivasi (X), mempunyai hubungan yang searah atau berbanding lurus dengan variabel terikatnya atau Wirausaha (Y). Artinya, jika variabel $\mathrm{X}$ 
mengalami kenaikan maka variabel terikatnya $\mathrm{Y}$ juga ikut mengalami kenaikan, dan jika variabel $\mathrm{X}$ mengalami penurunan, maka variabel terikatnya $\mathrm{Y}$ akan mengalami penurunan.

\section{2) Uji Hipotesis}

Langkah-langkah pengujian untuk koefisien regresi untuk menjawab hipotesis penelitian dengan cara membandingkan nilai $t_{\text {hitung }}$ dengan $t_{\text {tabel }}$ pada taraf nyata $5 \%$. Mengambil keputusan dengan kriteria jika $t_{\text {hitung }}>t_{\text {tabel }}$ maka Hipotesis benar atau teruji dan jika $t_{\text {hitung }}<t_{\text {tabel }}$ maka hipotesis salah atau tidak teruji.

Berdasarkan tabel 4.8 diatas, nilai $\mathrm{t}_{\text {hitung }}$ variabel Motivasi (X) adalah sebesar 3,642 dan nilai $t_{\text {tabel }}$ dengan tingkat kepercayaan 95\%, karena nilai $t_{\text {hitung }}$ lebih besar dari pada nilai $t_{\text {tabel }}(3,642>2,026)$ atau nilai probabilitas $(0,001)$ jauh lebih kecil dari pada nilai $\alpha(5 \%)$ maka dapat disimpulkan bahwa hipotesis dalam penelitian ini yang mengatakan bahwa Motivasi berpengaruh signifikan terhadap wirausaha Remaja Batu Ampar Pelaihari yang Berbisnis Online.

\section{3) Implikasi Hasil Penelitian}

Hasil penelitian menunjukkan faktor motivasi dapat mendorong Remaja Batu Ampar Pelaihari dalam Berbisnis Online. Untuk itu Remaja Batu Ampar Pelaihari harus berinovasi lagi dalam produk yang dijual. Kedepannya tidak hanya sebagai resseler namun juga bisa menjadi pelaku industri dengan menjual produk-produk lokasi di daerahnya.

Peran Pemerintah Daerah juga diperlukan dalam memotivasi remaja untuk berwirausaha agar angka pengangguran daerah bisa berkurang dan Batu Ampar Pelaihari bisa berkembang dengan masyarakatnya yang sejahtera.

\section{KESIMPULAN}

1) Berdasarkan hasil pembahasan menunjukkan bahwa variabel bebas memiliki koefisien regresi positif. Hal ini berarti variabel Motivasi (X), 
mempunyai hubungan yang searah atau sebanding lurus dengan variabel terikatnya atau Wirausaha (Y). Artinya, jika variabel $\mathrm{X}$ mengalami kenaikan maka variabel terikatnya $\mathrm{Y}$ juga ikut mengalami kenaikan, dan jika variabel $\mathrm{X}$ mengalami penurunan, maka variabel terikatnya $\mathrm{Y}$ akan mengalami penurunan.

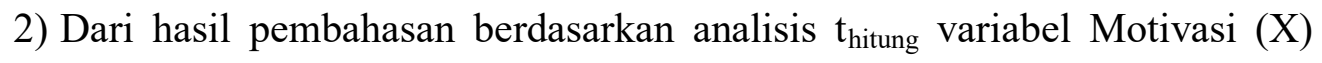
adalah sebesar 3,642 dan nilai $t_{\text {tabel }}$ dengan tingkat kepercayaan 95\%, karena nilai $t_{\text {hitung }}$ lebih besar daripada nilai $t_{\text {tabel }}(3,642>2,026)$ atau nilai probabilitas $(0,001)$ jauh lebih kecil dari pada nilai $\alpha(5 \%)$ maka dapat disimpulkan bahwa hipotesis dalam penelitian ini yang mengatakan bahwa Motivasi berpengaruh Signifikan terhadap Wirausaha Remaja Batu Ampar Pelaihari Yang Berbisnis Online.

\section{Saran-Saran}

1) Hasil penelitian menunjukkan faktor Motivasi dapat mendoronng remaja Batu Ampar berbisnis online, untuk kedepannya para remaja yang sudah atau akan berbisnis online lebih berinovasi pada produk yang dijual guna untuk menarik minat para pelanggan.

2) Peran pemerintah daerah juga diperlukan dalam memotivasi remaja untuk berwirausaha agar angka pengangguran daerah bisa berkurang dan Kecamatan Batu Ampar Pelaihari bisa berkembang dengan masyarakatnya yang sejahtera.

\section{DAFTAR PUSTAKA}

Basuki, 2015, Pengaruh Praktik Sumber Daya Manusia Strategik Dan Knowledge Management Terhadap Kinerja Organisasi, Jurnal Komunikasi Bisnis dan Manajemen, Vol.2 No.4 Juli 2015.

Basuki, 2021, Pengantar Metode Penelitian Kuantitatif, Penerbit Media Sains Indonesia, Bandung.

Dessler, Gary. 2007. Manajemen Sumber Daya Manusia, Alih Bahasa : Eli Tanya,. Penyunting Bahasa : Budi Supriyanto, Indeks, Jakarta.

Ghozali, Imam, 2005. Aplikasi Analisis Multivariate Dengan Program SPSS, Edisi Keempat, Penerbit Universitas Diponegoro. Semarang.

Hasibuan, Malayu S.P. 2005. Manajemen Sumber Daya Manusia, Edisi Revisi. Bumi Aksara, Jakarta. 
2010. Manajemen Personalia dan Sumber Daya Manusia. BPFE. Yogyakarta.

Kurniawan, 2006. Transformasi Pelayanan Publik. Pembaharuan. Yogyakarta.

Mangkunegara. 2008. Manajemen Sumber Daya Manusia. PT. Remaja Rosdakarya. Bandung.

Marihot T. E. Hariandja. 2005. Manajemen Sumber Daya Manusia, Pengadaan, Pengembangan, Pengkompensasian, dan Peningkatan Produktifitas Pegawai. Grasindo. Jakarta.

Mathis \& Jackson. 2006. Human Resource Management, alih bahasa. Salemba Empat. Jakarta.

Rivai, Veithzal. 2011. Manajemen Sumber Daya Manusia untuk Perusahaan dari Teori ke Praktik. PT. Raja Grafindo Persada. Jakarta.

Sastrohadiwiryo, 2012. Manajemen Tenaga Kerja Indonesia, Edisi 2. PT. Bumi Aksara. Jakarta.

Sutrisno. 2009. Manajemen Sumber Daya Manusia Edisi Pertama. Kencana Prenada Media Group. Jakarta.

Suwatno, Yuniarsih. 2003. Manajemen Sumber Daya Manusia, Cetakan ketiga. CV Alfabeta. Bandung.

Widyanti, Rahmi; 2019; Perilaku Organisasi: Teori dan Konsep, Repository Uniska MAB, Banjarmasin.

Widyanti, Rahmi; 2021; Perilaku Organisasi: Teori dan Konsep, Penerbit Media Sains, Bandung

Widyanti, Rahmi; Basuki; Mursanto; 2021, Meningkatkan Kepuasan Kerja Karyawan Melalui Perencanaan Karir Individu, Al-Kalam Jurnal Komunikasi, Bisnis Dan Manajemen 8 (2), 127-138. 